and examining thousands of scientific publications from the past 100 years or more. But the US\$1 million needed to create the database network is expected to save much more than that in the costs of contesting individual patents in foreign courts.

"We do not have the time or money to fight each patent," says Mashelkar. "The answer is to ensure that the patent is not awarded in the first place, by making databases of traditional knowledge available to patent examiners."

The Council of Scientific and Industrial Research has set up a unit in Pune, near Mumbai (formerly Bombay), to digitize traditional knowledge, and Mashelkar, who

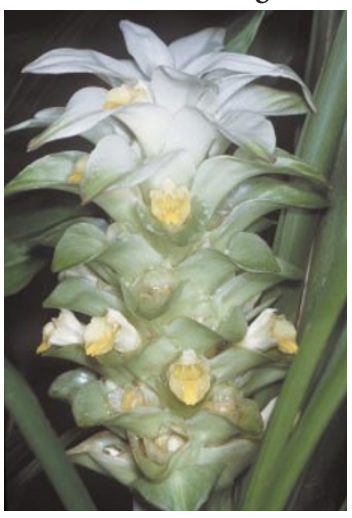

heads the

council, says

that the work

will be

completed in

one year.

He points out that the US

Patent and

Trademark

Office

(USPTO)

suggested to

India that it

Hands off: India blocked a US should create attempt to patent turmeric. the database. According to

USPTO, the turmeric patent might not have been issued if such a database had existed. In a letter to Mashelkar last month, USPTO official Robert Saifer admitted that the examiner who issued the patent "was not aware" of literature on the use of turmeric in wound healing in India.

K. S. Jayaraman
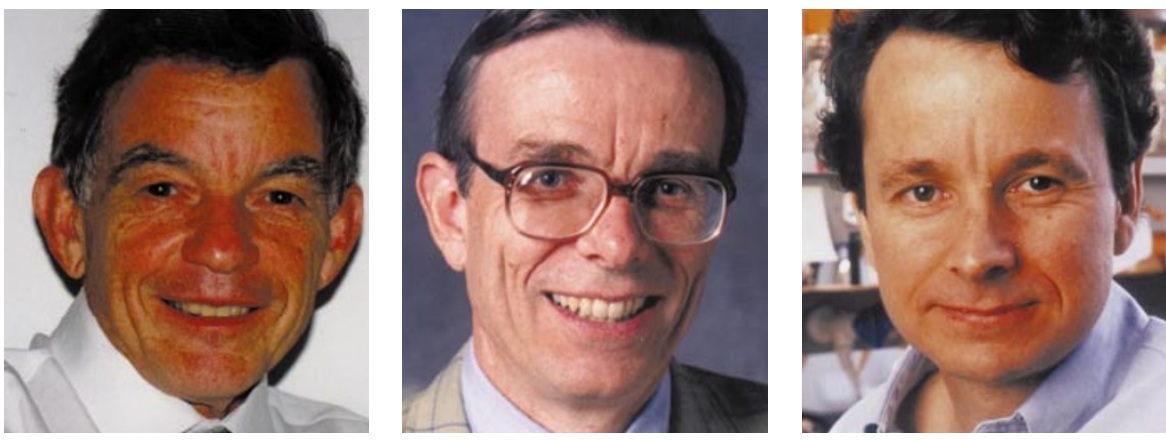

\title{
Lasker awards honour three pioneers in ion channels
}

\section{London}

Research that pioneered the understanding of electricity in biology was this week rewarded when three scientists shared the Albert Lasker award for basic medical research. Clay Armstrong of the University of Pennsylvania School of Medicine, Bertil Hille of the University of Washington, Seattle, and Roderick MacKinnon of the Rockefeller University in New York were recognized for their work on ion-channel proteins. Lasker awards are widely seen as highly significant, as many recipients subsequently win Nobel prizes.

Ion channels are holes in the membranes of cells that control the movement of ions, governing the electrical potential of membranes and intracellular signalling. They are basic to the body's electrical system, and control phenomena such as nerve impulses, muscle contraction and cardiac rhythm.

Armstrong was recognized for his work in elucidating the excitability of cell membranes and ion-channel gating. In the 1970s, Armstrong and Hille were among the few who believed that ion channels existed. Hille, who has worked for many years on various ion channels, is widely seen as one of the founders of this field. He showed that channels are independent physical entities within the membrane, and that they are selective to specific ions.

Potassium channels are among the most important molecules in the electrical signalling system. MacKinnon has been honoured for his work on the structure and function of these channels. $\mathrm{He}$ produced the first molecular description of an ion-selective channel. His 1998 paper in Science on the crystal structure of potassium channels was a crucial step forward for this field and sparked much new research.

Natasha Lode

\section{Coordinate international space science, meeting told}

\section{Munich}

Leading European space scientists have urged international space agencies to coordinate their research missions to ensure that they complement, rather than duplicate, each other.

At a meeting of the European Space Agency's (ESA) top-level science advisory committee and its science programme committee in Naples last week, scientists said that, apart from the Mars International Coordination Programme, cooperation between space-science disciplines is not as well established as it should be.

The committees, representing the astronomy, planetary-science and fundamental physics communities, met to discuss the scientific priorities for the ESA over the next decade. They noted that the major missions of the three largest space agencies are becom- ing increasingly similar.

For example, within less than a year, each will have launched X-ray observatories. The US space agency NASA's Chandra was launched in July, the ESA's XMM will launch in December (see opposite) and Japan's Astro-E will launch early next year. All three are also planning missions to Mercury.

The ESA's executive will consider ways of coordinating between disciplines, possibly at the level of the agencies' scientific advisory committees, to ensure complementarity of approach.

At the meeting, the ESA's executive said that the agency's science directorate will announce the opportunity for two mediumsized, 'flexible' missions in the coming weeks.

The executive also said that the ESA's next large, 'cornerstone' mission will be decided next June. The choice is between a journey to
Mercury, called Colombo, and an astrometry project called GAIA.

One of the two flexible missions, to be selected in a free competition next September, will probably be a contribution to the Next Generation Space Telescope, the NASA-led successor to the Hubble Space Telescope. Decisions about the second will be influenced by the choice of the next cornerstone mission, as the ESA aims for a balance between disciplines.

The science programme committee also approved the ESA's first technology mission, SMART-1, to be launched in November 2002. This will test electricpropulsion technologies for deep-space travel on a lunar mission. Small experiments will also fly on the mission, gathering X-ray and infrared spectroscopy data about the Moon's surface. Alison Abbott 